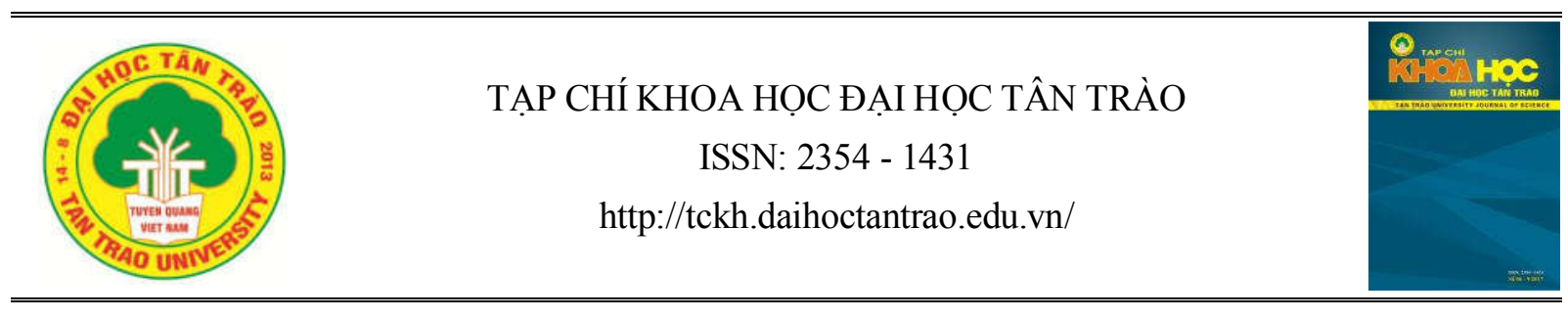

\title{
Phương pháp co bản phục hồi chức năng cho trẻ có rối loạn phát triển
}

\author{
Nguyễn Thị Xuân Dung ${ }^{a}$, Trần Thu Hương ${ }^{a}$
}

${ }^{a}$ Trường Đại học Điều dương Nam Định

\section{Thông tin bài viết}

Ngày nhận bài:

21/5/2019

Ngày duyệt đăng:

10/6/2019

\section{Tù khóa:}

Phục hồi chưc năng; phưong pháp phục hồi chưc năng; trẻ em; trẻ tụ kỷ; trẻ rối loạn phát triển.

\section{Tóm tắt}

Trẻ em có rối loạn phát triển ngày một gia tăng khiến cho các bậc cha mẹ lo lắng, gặp nhiều khó khăn trong việc giáo dục con cái. Có nhiều bệnh viện, trung tâm, cơ sở can thiệp phục hồi chức năng cho trẻ rối loạn phát triển nhưng ở mỗi nơi lại thực hiện các phương pháp khác nhau, không thống nhất. Bài viết này giới thiệu một số phương pháp cơ bản phục hồi chức năng cho trẻ có rối loạn phát triển nhằm giúp gia đình, trường học, các cơ sở can thiệp giáo dục trẻ em và sinh viên ngành $\mathrm{Y}$, tâm lý học, công tác xã hội, và giáo dục đặc biệt có thêm thông tin định hướng về các phương pháp can thiệp này.

\section{1. Đặt vấn đề}

Hiện nay tình trạng trẻ em có rối loạn phát triển ngày một gia tăng và ngày càng phổ biến ở Việt Nam. Số lượng chưa được thống kê đầy đủ nhưng theo thống kê sơ bộ của Bộ LĐTBXH, riêng trẻ em mắc chứng tự kỷ cả nước có khoảng 200.000 người [4]. Con số này không ngừng tăng lên, tuy nhiên việc điều trị cũng gặp không ít thách thức. Bởi vì, phương pháp phục hồi chức năng cho trẻ có rối loạn phát triển rất đa dạng, nhiều chuyên ngành tiếp cận. Hiện nay, nhiều gia đình đưa trẻ đến các cơ sở can thiệp khác nhau và trẻ được can thiệp theo nhiều hướng tiếp cận, đã dẫn đến có những khó khăn trong việc định hướng về phương pháp phục hồi chức năng cho trẻ có rối loạn phát triển. Bài viết này dựa trên cơ sở nghiên cứu lý luận và đúc kết kinh nghiệm làm việc đưa ra một số phương pháp cơ bản trong phục hồi chức năng cho trẻ có rối loạn phát triển để các bậc cha mẹ, giáo viên, sinh viên ngành Y, tâm lý học, công tác xã hội, giáo dục đặc biệt và người làm công tác phục hồi chức năng có thêm những hiểu biết khi làm việc với trẻ em.

\section{Phương pháp cơ bản phục hồi chức năng cho trẻ có rối loạn phát triển}

\subsection{Các khái niệm liên quan}

a. Thế nào là trẻ có rối loạn phát triển?

Khi một đứa trẻ có những thái độ đáp ứng hoặc hành vi không bình thường, không phù hợp với cách ứng xử như những trẻ khác cùng độ tuổi, trẻ có những hạn chế về giác quan, về vận động, nhận thức, ngôn ngữ và giao tiếp xã hội...chúng ta gọi đó là những trẻ có tình trạng rối loạn phát triển, rối nhiễu tâm lý. Như vậy, một đứa trẻ khỏe mạnh, không có rối loạn phát triển là đứa trẻ không chỉ cần tăng trưởng tốt về chiều cao và cân nặng, mà còn phải có một trí tuệ tương ứng với lứa tuổi. Trẻ có rối loạn phát triển là những trẻ em gặp vấn đề như khuyết tật trí tuệ (trễ về phát triển), rối loạn phổ tự kỉ, tăng động giảm tập trung; trễ về phát triển ngôn ngữ...gặp khó khăn trong sự phát triển nhận thức, trí tuệ, ngôn ngữ, vận động.[4]

Hai nhóm trẻ thuờng có tình trạng rối loạn phát triển:

- Thứ nhất, các trẻ bị khuyết tật, có những tổn thương về cơ thể và giác quan ( như khiếm thính, khiếm thị, bại liệt, bại não.v.v. ); trẻ có những rối nhiễu tâm lý.

- Thứ hai, trẻ không thể tham gia các hoạt động giáo dục bình thường, hay không thể bầy tỏ hết những cảm nghĩ và nhu cầu của mình nên tạo ra những ức chế dẫn đến tình trạng rối nhiễu.

Các dạng rối loạn phát triển: Rối nhiễu tâm thể; rối nhiễu hành vi; rối nhiễu nhân cách; lo âu, trầm cảm; khó khăn trong học tập; rối nhiễu ngôn ngữ; rối nhiễu vận động; rối nhiễu giới tính; rối loạn lan tỏa (rối loạn tự kỷ)... 


\section{Phương pháp phục hồi chưc năng}

Theo tổ chức $\mathrm{Y}$ tế Thế giới khái niệm về phục hồi chức năng ( $\mathrm{PHCN}$ ) được hiểu như sau: PHCN bao gồm các biện pháp y học, kinh tế, xã hội, giáo dục hướng nghiệp và kỹ thuật phục hồi nhằm làm giảm tác động của giảm khả năng và tàn tật, đảm bảo cho người tàn tật hội nhập xã hội, có những cơ hội bình đẳng và tham gia đầy đủ các hoạt động của xã hội.

Phương pháp phục hồi chức năng bao gồm các kỹ thuật, công nghệ khoa học kỹ thuật, các phương pháp, liệu pháp can thiệp tâm lý, vật lý, y khoa.[1]

Theo Bách khoa toàn thư mở Wikipedia tiếng Việt, có thể hiểu: Phục hồi chức năng là trả lại các chức năng bị giảm hoặc bị mất cho người tàn tật hoặc là giúp họ xử trí tốt hơn với tình trạng tàn tật của mình khi ở nhà hoặc ở cộng đồng. Phục hồi chức năng không chỉ huấn luyện người tàn tật thích nghi với môi trường sống mà còn tác động vào môi trường và xã hội tạo nên khối thống nhất cho quá trình hội nhập của người tàn tật.

Như vậy, PHCN chính là việc sử dụng các biện pháp, phương pháp và cách thức thực hiện phục hồi chức năng cho người bệnh. Do đó, có thể hiểu phương pháp phục hồi chức năng là cách thức, kỹ thuật mà nhà trị liệu, nhà giáo dục hoặc nhân viên y tế dùng để can thiệp, tác động với mục đích khôi phục lại các chức năng sinh lý, tâm lý, hồi phục lại những tổn thương, suy giảm chức năng cơ thể mà không cần phải sử dụng thuốc giúp người bệnh trở về trạng thái hoạt động tốt nhất nhằm cải thiện tình trạng sức khỏe.

\subsection{Phương pháp được sử dụng phục hồi chức} năng cho trẻ có rối loạn phát triển

Theo kết quả khảo sát nhu cầu sử dụng tài liệu hỗ trợ phục hồi chức năng cho trẻ tự kỷ ở Việt Nam tại 13 tỉnh/thành như Hà Nội, Hải Phòng, Nghệ An, Thừa Thiên-Huế, Đà Nẵng, TPHCM... cho thấy, hiện có tới 49 tài liệu liên quan đến rối loạn phổ tự kỷ đang được biết đến và sử dụng nhiều [2]. Con số này trong thực tế còn có nhiều hơn nữa, chưa có thống kê nào được đầy đủ.

Mới đây, Quỹ Bảo trợ trẻ em Việt Nam, Bộ LĐTBXH phối hợp khởi xướng Dự án "Nâng cao nhận thức về tự kỷ ở trẻ em Việt Nam” trong 5 năm (2018 2022) với các mục tiêu nâng cao nhận thức về trẻ em tự kỷ, đồng thời tuyên truyền vận động cộng đồng cùng tham gia vào các hoạt động can thiệp, hỗ trợ trẻ em tự kỷ, từ đó tạo cơ sở đề xuất chính sách cho trẻ em tự kỷ ở Việt Nam. [2]
Tuy nhiên, phần lớn chúng ta được biết và tiếp cận các tài liệu về rối loạn phổ tự kỷ ở trẻ em. Các tài liệu này chủ yếu đọc qua báo mạng, trang web, video trên mạng và các tài liệu phát tay, photo từ các khóa tập huấn chuyên môn, số sách có hội đồng khoa học đánh giá, được xuất bản lại rất ít.

Hiện nay các trung tâm, các trường đang áp dụng các phương pháp, cách thức khác nhau, chưa có tài liệu chung về trẻ có rối loạn phát triển. Dưới đây là các phương pháp phục hồi chức năng cho trẻ có rối loạn phát triển thường được dùng tại các bệnh viện, trường học, các trung tâm can thiệp cho trẻ có rối loạn phát triển.

\subsubsection{Phuong pháp trị liệu vật lý}

\section{Kỹ thuật vật lý trị liệu, vận động trị liệu}

Phương pháp này Kỹ thuật viên hướng dẫn là người nhà của trẻ và trẻ có thể tự luyện tập được với các thao tác trị liệu phục hồi chức năng đơn giản. Các động tác có thể tập thụ động, chủ động, có giúp sức, bài tập có kết hợp động tác, liên hoàn với các dụng cụ như: gậy, xe đạp, máy cơ học, ... kết hợp vận động trong nước và phương pháp thủy trị liệu. Mục đích của phương pháp này giúp trẻ tăng tuần hoàn máu, giãn cơ, trị đau, ngăn ngừa co rút, co thắt cơ,...Những bài tập trị liệu khá đa dạng kết hợp với nhiều dụng cụ khác nhau.

\section{Kỹ thuật vật lý trị liệu với co động học trị liệu}

Phương pháp trị liệu được sử dụng bằng các thao tác xoa bóp giúp trẻ tăng độ mềm dẻo cơ, giảm đau, tuần hoàn, tăng máu tới cơ, giãn mao mạnh,...bằng cách kích thích cơ học lên các mô mềm bằng áp lực, kéo giãn nhịp nhàng. Các thao tác này được sử dụng thường xuyên sẽ giúp trẻ thư thái tinh thần, giảm sự co cứng.

\section{Kỹ thuật vật lý trị liệu với tác nhân vật lý}

Đây là phương pháp điều trị phối hợp sử dụng những thiết bị sóng (vi sóng, sóng ngắn, siêu âm, từ trường, sóng xung kích) hoặc nhiệt giúp người bệnh phục hồi.

Hiệu quả của phương pháp này sẽ giúp người bệnh trị đau, kháng viêm, gia tăng tuần hoàn máu, giảm phù nề, thư giãn các cơ bị co thắt, co cứng; làm giảm sưng, kháng viêm, trị đau, gia tăng hiệu suất co cơ, tái tạo gân, tăng tuần hoàn máu; làm lành vết thương nhanh, điều hòa hoạt động thần kinh thực vật, kích thích phát triển xương, điều trị mất ngủ, rối loạn tiền đình,...tăng cường phân tán chất trung gian dẫn truyền đau... 


\subsubsection{Phuoong pháp trị liệu tâm lý, giáo dục phục} hồi chưc năng

Cùng với những phương pháp điều trị vật lý thì kỹ thuật phục hồi chức năng cũng dựa trên những thành tựu của khoa học tâm lý, giáo dục vào can thiệp phục hồi chức năng cho trẻ có những rối loạn về ngôn ngữ, tâm vận động, rối loạn cảm xúc, các kỹ năng giao tiếp lý trị liệu để hình thành nên một hệ thống các phương pháp can thiệp trị liệu tâm lý, giáo dục phục hồi chức năng cho trẻ có rối loạn phát triển. Dưới đây là một số phương pháp cơ bản:

\section{Phuoong pháp tham vấn cho gia đình}

Đây là phương pháp dùng để hướng dẫn, tham vấn, tư vấn cho cha mẹ trẻ cần tiếp cận và trang bị cho mình kiến thức từ internet, bệnh viện, giáo viên chuyên biệt, trung tâm dạy trẻ chuyên biệt... để là người trực tiếp can thiệp, điều trị cho con, giúp con khắc phục những điểm yếu như tập trung vào giảng dạy cách thức giao tiếp, ứng xử, các kỹ năng sống cơ bản, tăng cường khả năng vận động cho trẻ. Phần lớn gia đình là những người có thời gian bên trẻ nhiều hơn các chuyên viên phục hồi chức năng, cho nên các thành viên gia đình cần dành thời gian để giáo dục trẻ, vui chơi và làm việc với trẻ, góp phần củng cố kết quả can thiệp phục hồi, làm cho trẻ tiến bộ hơn khi được can thiệp ở các cơ sở y tế và giáo dục đặc biệt.

Gia đình giáo dục và tác động tới từng đứa trẻ riêng biệt, đứa trẻ sẽ nhận được sự chăm sóc chu đáo, tỉ mỉ, trẻ học được nhiều kĩ năng và kinh nghiệm hơn, có nhiều cảm xúc với những sắc thái phong phú. Sự quan tâm của nhiều người ở nhiều khía cạnh sẽ là điều kiện để đứa trẻ phát triển tốt các mặt trong đời sống.

\section{Phuoong pháp trị liệu ngôn ngũu}

Phương pháp này có thể kích thích bé phát triển ngôn ngữ bằng cách: dạy và khuyến khích trẻ luyện tập các cơ quan phát âm bằng cách thực hiện các động tác như: bặm môi, thổi bong bóng, phun mưa, tặc lưỡi...; thường xuyên nói chuyện với trẻ càng nhiều càng tốt; hát hoặc đọc truyện cho trẻ nghe; gọi tên trẻ; lặp lại các âm thanh, các từ trẻ phát ra, khen trẻ mỗi khi trẻ nói được những câu, từ rõ ràng hoặc đúng hoàn cảnh. Mục tiêu và phương pháp được soạn dựa vào khả năng ngôn ngữ của trẻ.

Phuong pháp ABA (Applied Behavior Analysis Phân tích hành vi úng dụng)

Phương pháp này dạy cho cá nhân trẻ theo những khả năng khác nhau, và có thể được sử dụng trong tất cả lĩnh vực: tự chăm sóc, lời nói và ngôn ngũ̃, kĩ năng ứng xử xã hội. Phương pháp phục hồi chức năng qua dạy từng kĩ năng trong mọi lĩnh vực (học các học, giao tiếp, xã hội, kiến thức, tự chăm sóc, vận động, chơi v.v).

Khi dạy cho trẻ, các giáo viên, nhà tâm lý sẽ dạy cho trẻ các kỹ năng cụ thể theo chủ đề các kỹ năng cơ bản như tìm kiếm, nghe và bắt chước, tắm, vệ sinh cũng như các kỹ năng phức tạp như đọc, nói chuyện và hiểu được quan điểm của người khác.

Cách thực hiện: Chia nhỏ thành các kỹ năng thành phần và được sắp xếp theo trình tự phát triển, từ đơn giản đến phức tạp. Mục tiêu chung và cuối cùng của phương pháp là để giúp mỗi trẻ hình thành các kỹ năng cơ bản, giúp trẻ về lâu về dài, sống độc lập và thành công ở mức có thể.

\section{Phương pháp trò chơi vận động, tuoong tác}

Là một phương pháp tác động qua vận động cơ thể giúp trẻ biểu lộ cảm xúc đồng thời qua vui chơi giúp trẻ phát triển các yếu tố hình thành nhân cách. Trò chơi sử dụng các yếu tố chơi, các trò chơi thích hợp để kích thích trẻ hoạt động, mở rộng hiểu biết về môi trường xung quanh và phát triển lời nói.

\section{Cách thục hiện:}

- Luyện tập cho trẻ thực hiện lặp đi lặp lại nhiều lần các câu nói, động tác, hành vi, cử chỉ, điệu bộ phù hợp với nội dung, yêu cầu giáo dục và hứng thú của trẻ.

- Dạy trẻ những hành động thao tác với đồ vật, đồ chơi: sử dụng các đồ vật, dụng cụ đơn giản phù hợp với mục đích và nội dung giáo dục.

- Hướng dẫn trẻ cùng làm theo và thao tác với đồ vật như sờ mó, cầm nắm, lắc, mở, đóng, chồng lên, và phối hợp vận động với các giác quan.

\section{Phuoong pháp Trị liệu phân tâm}

Phương pháp này chủ yếu là chơi và nói chuyện, nhằm giúp trẻ và gia đình giải tỏa những căng thẳng dồn nén trong quá khứ, hệ thống lại cấu trúc nhân cách của trẻ.

Nhà tham vấn sẽ trò chuyện với gia đình, trẻ về những lo lắng, những điều quan tâm, hứng thú. Thời gian trò chuyện được sắp xếp theo từng tình huống vấn đề nảy sinh cũng như nhu cầu của gia đình và bản thân trẻ mỗi ngày, mỗi tuần. Bối cảnh trò chuyện có thể diễn ra ở tại gia đình, công viên, văn phòng tư vấn tâm lý.

Phương pháp phân tâm sẽ giúp cải thiện bầu không khí gia đình, giúp mọi người thấu hiểu thực tại và chấp nhận thực tại tốt hơn, mọi người sẽ vui vẻ hơn trong giao tiếp và chăm sóc trẻ. Điều này giúp trẻ rối loạn 
phát triển cải thiện tình huống giao tiếp và hình thành sự tiếp xúc qua lại. Khuyến khích trẻ hợp tác trong mọi hoạt động sinh hoạt của gia đình, nhà trường và xã hội; từ đó, tình trạng rối loạn của trẻ được cải thiện dần dần.

\section{Phuoong pháp tâm vận động}

Mục đích của phương pháp là kích thích trẻ hoạt hóa hành vi. Hướng dẫn trẻ vận động (hoạt động) cơ thể nhằm mục tiêu tạo lập sự nhanh nhạy của hệ thần kinh và tác động đến phát triển tâm lý. Vận động về cơ thể trẻ càng tăng thì vận động về tâm lý tăng theo. Sự phát triển tâm lý sẽ kéo theo sự phát triển vận động. Phương pháp này giúp những trẻ em gặp các vấn đề khó khăn về tâm lý có khả năng phối hợp các chức năng tâm trí tản mạn, hướng trẻ đến những hoạt động tâm lý có ý nghĩa. Khả năng hợp tác của trẻ được tăng lên khi áp dụng phương pháp.

\section{Trò choi đóng vai}

Phương pháp được thực hiện trên cơ sở xây dựng tình huống, người đóng phải tưởng tượng mình là nhân vật khác, biểu lộ những buồn bực, nóng giận, vui vẻ hạnh phúc... mà vai diễn quy định. Đây cũng là hình thức tâm kịch mà nhà tham vấn cùng thân chủ xây dựng một vở kịch theo các tình huống tâm lý, giúp trẻ trải nghiệm với những xúc cảm, tâm trạng nhân vật trong vở kịch. Trò chơi đóng vai thể hiện mức độ cao trong phát triển nhận thức, nêu trẻ làm tốt phương pháp này thì cơ hội hòa nhập của trẻ hầu như bình thường, có thể tham gia tốt vào đời sống xã hội, cộng đồng.

\section{Phuoong pháp giáo dục đặc biệt}

Phương pháp giáo dục đặc biệt cho trẻ có rối loạn phát triển với các khiếm khuyết: trí tuệ, giao tiếp, xúc cảm, tình cảm, ngôn ngữ, tự phục vụ... Thông qua giáo dục sẽ giúp trẻ hiểu và có kỹ năng hòa nhập xã hội, tăng cường khả năng giao tiếp, giúp nhận thức sự vật và hiện tượng xung quanh, hiểu biết và quan tâm đến những ứng xử tình cảm của người khác, tăng cao khả năng hội nhập cộng đồng.

\section{Kết luận}

Cho đến nay, mặc dù đã có rất nhiều phương pháp phục hồi chức năng dành cho trẻ tự kỷ được áp dụng tại nhiều nơi trên thế giới, nhưng các phương pháp phục hồi chức năng dành cho trẻ có rối loạn phát triển còn chưa thống nhất, kết quả can thiệp còn rất hạn chế.
Vì không có chương trình khung, giáo trình chuẩn nên việc chữa trị cho trẻ có rối loạn phát triển hiệu quả không cao và gặp rất nhiều khó khăn. Sự không thống nhất về phương pháp phục hồi chức năng cũng do mỗi trẻ cần có phương pháp, cách thức dạy, cách để trẻ học, trẻ chơi khác nhau. Do đó, việc xây dựng các phương pháp can thiệp phục hồi chức năng cho trẻ có rối loạn phát triển đòi hỏi có sự phối hợp các chuyên gia trong lĩnh vực y tế, giáo dục và đặc biệt quan trọng là sự tham gia của gia đình và người thân của trẻ. Xu hướng hiện nay là dùng các phương pháp giáo dục cho trẻ rối loạn sau khi đưa ra chẩn đoán. Việc giáo dục trẻ tùy thuộc vào khả năng nhận thức và hành vi của trẻ; mục tiêu, chương trình và phương pháp đều được thiết kế dựa vào mức độ trí tuệ của trẻ.

\section{TÀI LIỆU THAM KHẢO}

1. Bộ Y Tế (2009), Tài liệu số 15 "Phục hồi chức năng trẻ tự kỷ" trong Bộ tài liệu "Phục hồi chức năng dựa vào cộng đồng” ban hành kèm theo Quyết định số 1213/QĐ-BYT ngày 15/4/2009.

2. Bộ LĐ-TB\&XH phối hợp trường Đại học sư phạm Hà Nội (2018), Tài liệu Hội thảo Hoàn thiện đề cuơng tài liệu hỗ trợ phục hồi chức năng cho trẻ em tự kỷ ở Việt Nam, tháng 9, Hà Nội,

3. Đại học Y Hà Nội (2010), Tài liệu Vật lý trị liệu phục hồi chức năng - Nhà xuất bản Y học Hà Nội 2010.

4. Hội khoa học Tâm lý - Giáo dục Việt Nam (2019), Phát triển năng lực chuyên môn và đổi móti quản lý trong hoạt động can thiệp trẻ có rối loạn phát triển, NXB ĐHQG, Hà Nội.

5. Nguyễn Thị Thanh (2014), Biện pháp phát triển kỹ năng giao tiếp cho trẻ tự kỷ 3-4 tuổi, Luận án Tiến Sỹ Khoa học giáo dục, Bộ giáo dục và đào tạo, Viện Khoa học giáo dục Việt Nam.

6. Đỗ Thị Hương Thảo (2013), “Các yếu tố ảnh hưởng đến hiệu quả của quá trình can thiệp sớm cho trẻ rối loạn phổ tự kỷ”, Báo cáo khoa học toàn văn, Viện khoa học giáo dục Việt Nam, tr.57 - 62.

7. Nguyễn Xuân Thắng (2012), “Đánh giá sự cải thiện kỹ năng phát triển của trẻ bị tự kỷ sau can thiệp ngôn ngữ trị liệu”, Luận văn Bác sỹ chuyên khoa cấp II, Đại học Y Hà Nội. 


\title{
Basic rehabilitation method for children with developmental disorders
}

\author{
Nguyen Thi Xuan Dung, Tran Thu Huong
}

\section{Article info}

Recieved:

21/5/2019

Accepted:

$10 / 6 / 2019$

Keywords:

Rehabilitation;

Rehabilitation methods;

children; autistic

children; children with

developmental disorders.

\begin{abstract}
Children with increasing developmental disorders make parents anxious and difficult to educate their children. There are many hospitals, centers, and rehabilitation facilities for children with developmental disorders but different places, different methods and inconsistencies are implemented. This article introduces some basic rehabilitation methods for children with developmental disorders to help families, schools, and educational facilities to educate children and students in medicine, psychology, and public Social and special education has more direction information on these interventions.
\end{abstract}

